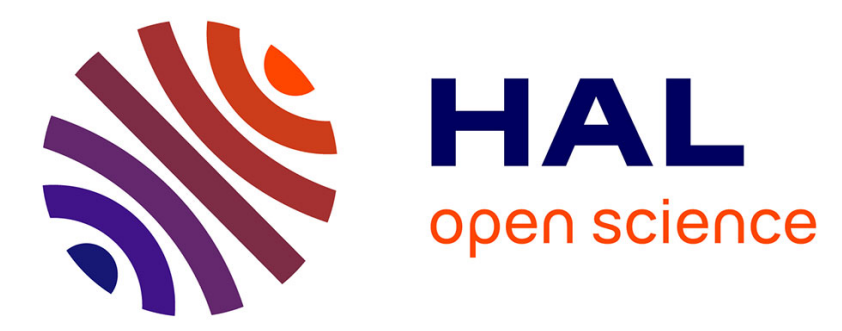

\title{
A-disciplinary considerations of two networks of local climate energy initiatives
}

\author{
Pia Buschmann, Peter Moser, Alain Nadai, Yannick Régnier
}

\section{To cite this version:}

Pia Buschmann, Peter Moser, Alain Nadai, Yannick Régnier. A-disciplinary considerations of two networks of local climate energy initiatives. Local Environment, 2018, pp.1-20. halshs-01962715

\section{HAL Id: halshs-01962715 \\ https://shs.hal.science/halshs-01962715}

Submitted on 3 Jun 2019

HAL is a multi-disciplinary open access archive for the deposit and dissemination of scientific research documents, whether they are published or not. The documents may come from teaching and research institutions in France or abroad, or from public or private research centers.
L'archive ouverte pluridisciplinaire HAL, est destinée au dépôt et à la diffusion de documents scientifiques de niveau recherche, publiés ou non, émanant des établissements d'enseignement et de recherche français ou étrangers, des laboratoires publics ou privés. 


\title{
A-disciplinary considerations of two networks of local climate energy initiatives
}

To be published in Local Environment - Paper part of the Special issue entitled:

"Unlocking Energies, Unpacking the Entanglements and Temporalities of Local Initiatives"

Author Draft; provisional version - Please do not quote or disseminate without the permission of the authors

\section{Pia Buschmann}

Project Manager, Competence Network ecentralised Energy Technologies e. V. (deENet), Kassel, Germany, 2013-2016

pb.buschmann@gmail.com

Pia Buschmann was responsible for coordinating the actions of the German 100\%-

Renewable-Energies-[RE]-Regions network within the European 100\% Renewable Energy

Sources [RES] Communities project. She also facilitated the international outreach of the $100 \%$-RE-Regions network as part of the 100\%-RE-Campaign and the international dialogue fora of the annual 100\%-RE-Regions conference.

\section{Peter Moser}

Division Manager, Renewable Energies and Regional Climate Protection, Competence Network decentralised Energy Technologies e. V. (deENet), Kassel, Germany p.moser@ide-kassel.de

Peter Moser is an interdisciplinary expert for sustainable energy strategies and instruments focused on the regional level. He was the project manager and key innovator of the $100 \%$-RERegions project in Germany. From 2007 to 2016, he was division manager at deENet. From 2012 to 2018 he was also the head of the Department of Sustainable Regional Development at the IdE, Institute of decentralised Energy Technologies.

\begin{abstract}
Alain Nadaï ${ }^{1}$
Interdisciplinary social scientist, CIRED-CNRS, Nogent-sur-Marne, France nadai@centre-cired.fr

Alain Nadaï is an interdisciplinary social scientist at CIRED, the International Research Centre on Environment and Development, which is part of the French CNRS. His research activity is focussed on environmental controversies, landscape policies and energy transition policies and processes.
\end{abstract}

\section{Yannick Régnier}

Project manager, CLER - Network for the energy transition, Montreuil, France yannick.regnier@,cler.org

Yannick Régnier is responsible for 'Energy and Territories' programme within CLER. He has initiated and manages the Positive Energy Territories Network from 2011. He has coordinated the European projects RES Champions League (2008-2011) and 100\%-RES Communities (2012-2015) (Intelligent Energy Europe programme).

\footnotetext{
${ }^{1}$ Corresponding author: Alain Nadaï - Centre International de Recherche pour l'Environnement et le Développement - Jardin Tropical, 45 bis, Avenue de la Belle Gabrielle, 94736 Nogent -sur-Marne Cedex, France - Tel. 33 (0) 143947387 - $\underline{\text { nadai@,centre-cired.fr }}$
} 


\begin{abstract}
In France and Germany, significant networks of local initiatives have developed around energy issues. This article brings practitioners' viewpoints into discussion. It presents the way in which two of these networks - the CLER-network for the energy transition (France) and the 100\% RE Regions network (Germany) - each identifies itself, describes its action and build-up process in relation to government action, and conceives of justice issues in the field of climate energy policy.

The analysis shows that these two networks share a lot, including political ends (localisation of energy production, empowerment of rural territories), but practice quite differently as intermediaries for local initiatives. This suggests overcoming the transition management vs grass roots divide present in the literature and pay more attention to hybrids. It also brings emphasis on a type of intermediary's work, which has not been covered by the academic literature, namely that of tinkering with multiple supports and embedding action in local-national-supranational networking in order to maintain continuity.

In discussing justice dimensions, we emphasize that motives or ends of action are only reflectively related to ideas of justice: justice issues seem bound up with a politics of assembling, either as a marker of federative of action (all fighting for justice) or as a potentially divisive issue.
\end{abstract}

Keywords : Climate-energy; local initiatives; practitioners view; entanglements; justice issues

\title{
Introduction
}

This paper presents the recent experience of two networks of local climate energy initiatives which have been developed in France and in Germany. It stems from a seminar on local climate energy initiatives that was held in Paris in March 2015 and concluded a French research project (Climencored, coord. A. Nadaï) including the CLER-Réseau pour la Transition Energétique. Yannick Régnier, the representative of the Positive Energy Territories network ('TEPOS', CLER-Réseau pour la Transition Energétique, France) and Peter Moser, the promoter of the $100 \%$ RE-Regions network (deENet, Germany), were asked to present there their respective network, its history, emergence, activities and the way they foresaw its future. Yannick started the 'Energy and Territories' programme within CLER ten years ago and has coordinated it until now. Peter has contributed (since 2007) to the management and coordination of both deENet and the 100\%-RE network. Their viewpoints are thus based on these leading roles and embed regular feedback from key network members.

At the time of the Paris seminar, these representatives considered their networks as French-German homologues: they both gathered what they considered to be local initiatives, they both flagged a 100\% renewable energy (RE) target, and they both were national networks without genuine equivalents at the European or international level - even if they shared commonalties with Climate Alliance or ICLEI ${ }^{2}$, a recent 100\%-RE network set-up in relation with a $100 \%$-RE campaign co-initiated by deENet ${ }^{3}$.

\footnotetext{
${ }^{2} \mathrm{http}: / /$ www.iclei.org/activities/agendas/low-carbon-city/iclei-100re-cities-regions-network.html

3 http://go100re.net
} 
After both speakers briefly presented their networks, the subsequent discussions pointed out salient differences in the ways each defined their network and conceived of its action as well as in the way they defined local initiatives. The idea thus emerged to have a try at jointly exploring further what we could learn from this material by writing a paper. Pia Buschmann, project coordinator at deENet since 2013 and $\mathrm{PhD}$ student in political science, joined us in order to assist Peter in this task.

The present paper first details the working process through which we attempted to structure what we consider an 'a-disciplinary' account of the networks (§. 1). Part 2 and part 3 then successively present the resulting account of each network. Part 4 presents the lessons that can be derived from these accounts (§. 4). This last part was elaborated in a slightly different way, with the 'academic' author A. Nadai taking the lead in the writing and trying to elaborate lines of inquiries that were of interest to the special issue, such as the way in which these networks develop multiple entanglements and approach justice issues. The other authors have discussed and amended this part of the text.

The analysis shows that the two networks share a lot, including political ends which bring them close to the politics of the grassroots (localisation of energy production, empowerment of rural territories), but practice quite differently as intermediaries for local initiatives. In several respects, one network is closer to the practice of intermediaries as described by the transition management strand, whereas the other's practice is better captured by the grassroots initiative strand of analysis. While this invites us to overcome academic divides and pay attention to hybrids, it also brings emphasis on a work of intermediaries which has not been considered in the academic literature (Hargreaves et al. 2013; Geels and Deuten, 2006): the work of tinkering with multiple supports and levels (local-national-supranational) which these network have to undertake in order to maintain continuity.

We also emphasize that motives or ends of action, which incorporate distributive or recognition concerns - such as, for instance, recognising differences in endowments and capabilities betw. small and big players in the energy transition - are only reflectively related to ideas of justice: justice issues are identified as markers only after probing. As has been pointed out in the literature (Jonet and Servigné, 2013, Fernandes-Jesus et a. 2017; Bailey et al. 2018) justice issues seem bound up with a politics of assembling, either as a marker of federative of action (all fighting for justice) or as a potentially divisive issue (justice considerations presuppose recognising and flagging differences).

\section{Collectively elaborating networks accounts}

The term 'a-disciplinary' means that our primary priority in organising the material was not to align it with academic ways of framing and analysing local initiatives. While the speakers at the Paris seminar proposed a frame for their interventions, the dimensions they foregrounded in answering the request were of their own choice. Our goal was thus to work on the basis of these dimensions. Justice issues, which were one of the themes of the special issue, were not spontaneously covered during the seminar: they have been added subsequently in the writing.

The working process started with asking each speaker to write down his presentation. The written material, however, was too copious to be made sense of for an academic journal. We thus entered a process that may be called 'collective re-writing'. The 'academic' author, assumed to be accustomed to ways of developing academic papers, listed the main dimensions developed in each written presentation and redistributed the contents under three headings, each organised by a set of questions. Each network representative then rewrote this (raw) material as if answering the questions. The many exchanges that followed mainly 
consisted in the 'academic' author playing the role of an 'interviewer'. He was asking the other authors, now become 'informants', to clarify their statements and sort out what was part of the network self-presentation discourse built up over time from what was part of its actual history and practice. The last step consisted in summarizing commonalties and differences, and in exchanges about the lessons that could derived from these stories.

This method had the advantage of allowing us genuinely to share the writing. The academic author adopted a framing and facilitating role. The other three authors, all practitioners, ended up playing the role of informants, while still genuinely contributing to the authorship by rewriting, criticising and amending the text and the resulting lessons. The successive reformulations allowed us to agree on accounts, which of course are constructs, which we felt reflected the recent history of each network as well as the way in which each of them represented itself.

Drafting the paper and having it reviewed also gave us occasion to reflect upon our choice of jointly addressing these two specific networks in a paper. The comparison was triggered by Yannick and Peter's initial intuition that their networks were homologues. Each in its country enjoys legitimacy and plays a role that is recognised by both partner networks and national institutions at the crossroads of sustainable energy (100\%-RE objective) and rural territories.

If we want to call them simply networks of 'local initiatives', however, so as to avoid giving them too narrow an initial connotation, ${ }^{4}$ it is important to compare them with other entities, such as the 'Transition Network', 'Community renewable energy', 'grassroots initiatives' and 'innovation niches', which also have a 'local' dimension and have been discussed in the academic literature. ${ }^{5}$ We therefore observe that TEPOS and the $100 \%$-RE network seem to share a few distinctive features. The initiatives they gather together always posit local authorities - sometimes energy or farming cooperatives - as major players in the energy transition. They pursue a 100\%-RE target in order to create local value, improve resilience, tackle fuel poverty and enhance democracy. The type of action they foster deals with energy strategies and is developed on a territorial scale: they pursue a territorial interest, possibly in relation to public policies (territorial biogas units, housing retrofitting programmes, sustainable mobility plans), on the basis of which they might be expected to set a proper framework and provide financial support.

By comparison, the 'Transition Network', for instance, is more exclusively based on citizen actions, developed on the scale of small collectives, and geared towards the demonstration of concrete alternatives to oil and gas depletion ${ }^{6}$. This network, as well as many grassroots initiatives, also keeps its distance from (when it is not in defiance to) state action and local authorities, advocating alternatives to current institutions ${ }^{7}$. All the same, socalled 'innovation niches', as they have been defined by the transition management literature ${ }^{8}$, are geared towards upscaling and regime change, which is not necessarily what the TEPOS

\footnotetext{
${ }^{4}$ Thus, here, the term 'local' refers neither to a single scale initiative or to ideas of 'localism' or 'localisation', even if the networks under consideration may convey certain dimensions associated with these ideas. For a discussion of the meaning of these terms, see Felicetti (2013) and Taylor (2012).

${ }^{5}$ It is not our purpose here to survey this literature, but some examples include the grassroots perspective (e.g. Seyfang, 2010; Seyfang \& Smith, 2007; Seyfang et al., 2013; Middlemis and Bradley, 2010; Walker \& Devine-Wright, 2008), community energy (Taylor Aiken, 2015, Van de Grift et al., 2017), the Transition Movement literature (e.g. Felicetti, 2013; Feola and Nunes, 2014; Taylor, 2012), the STS (e.g. Van der Schoor at al., 2016 ; Yalçın-Riollet et al., 2014) and MLP literature (e.g. Schot and Geels, 2008).

${ }^{6}$ Even if its position in favour of the localisation of production (for a discussion of this idea, see Felicetti, 2013 and Taylor, 2012), for instance, may find some echo in the TEPOS Charter or in the German 100\%-RE vision.

${ }^{7}$ Although the 'Transition Network', positioning towards institutions and political processes is of course not unified (see Fernandes-Jesus et al., 2017)

${ }^{8}$ For a characterisation of these niches, see Schot and Geels, 2008.
} 
and the 100\%-RE network representative envision for the members of their network. We shall come back to this point later.

Last but not least, albeit they are located in different countries, our goal is not to develop a methodical comparison of energy policy institutions in these two countries. It is rather simply to point out two singular histories of network practices as experienced by their protagonists, add to existing descriptions, and discuss entanglements and justice issues. Much has been written about local initiatives and from different perspectives. ${ }^{9}$ A practice-centred account of the emergence and action of national networks of local initiatives seems worth adding to these perspectives, especially if we want to understand how these networks manage to build continuity.

The accounts are presented successively for each network ( $\$ .2$ TEPOS; $\S .3100 \%$-RE) and structured as follows: $\mathrm{i} /$ the network, its (self-) definition and emergence; ii/ the definition of what a 'local initiative' is and how this guides (or not) actions and methods; iii/ justice issues that are foregrounded by the network; and iv/ the relation to public policy, its evolution and the vision for the short-term future of the network.

\section{CLER - Réseau pour la Transition Energétique and the TEPOS network}

\section{The Network}

\section{Q. How would you define your network and its objective today?}

The Network of 'Positive Energy Territories' (TEPOS network) assembles mainly rural local authorities committed to address energy issues in relation to and in favour of territorial development. As of spring 2018, it gathered together about 120 members. It is included in an existing (since 1984) registered environmental association: the CLER. CLER promotes a new energy model in which local governments play the main part, since energy choices imply lifestyle options and all citizens need to act and be committed to change.

TEPOS members sign a charter declaring that they share the idea of acting in favour of local development, job creation, social and territorial cohesion, citizen participation and the environment. The idea of energy autonomy is also important. It is defined as the possibility for an individual or a group of actors to depart from external laws and institutions - such as raw material, financial or energy markets, centralised energy systems outside regional controls - to get a grasp on energy futures. The network supports its members by sharing experiences, practices and knowledge.

\section{Q. When and how did your network emerge?}

In the genesis of the TEPOS movement, the definition of the concept and the creation of the network tended to be inseparable and were the joint initiative of Le Mené territory (Britain) ${ }^{10}$ and CLER. The TEPOS network was inaugurated in June 2011 within the framework of the first national TEPOS conference organised by Le Mené (under preparation since 2010). Six local authorities were among its founding members. This conference initiated a perennial cycle of conferences, which have become a renowned event, assembling more than 400 participants.

\footnotetext{
${ }^{9}$ See footnote 6 .

${ }^{10}$ Le Mené is a territory that was considered a pioneer in local development strategy in the 1960s; more recently, it has been seen as a leader in the field of climate energy strategy. Yacin et al, 2014
} 
Q. What were the main steps and the politics in the network's process of structuration?

As of 2010, CLER expected it to be difficult to find significant institutional funding to develop its TEPOS initiative in France. It decided to build on its previous experience with European projects and successfully applied to the Intelligent Energy Program with the ' $100 \%$ RES Communities' project (2012-2015, 13 partners, 10 countries). The project allowed CLER to finance a TEPOS project manager and our actions to gain momentum all over Europe. The existence of flagship territories for the TEPOS concept (e.g. Le Mené, Montdidier) and the positive response from other territories, media and public institutions created a snowball effect, which gave the TEPOS movement visibility. In 2012 and 2014, several French regions initiated TEPOS supporting programmes together with regional directorates of the French energy agency. Over these years, the territories that gained support from these programmes represented most of the newcomers in the TEPOS network; there were not many.

At the end of 2014, a national 'TEPCV' ('Positive Energy Territory for the Green Growth') programme was launched within the new French energy transition Law ${ }^{11}$. This was undertaken under the leadership of the incoming Minister of Environment Ségolène Royal, former president of one supporting region. Such an official call for local territories to play a role in the energy transition was a first in France. Since 2015, this has enticed national institutional partners to start financing the CLER-TEPOS programme.

Q. Has the objective of your network evolved since its creation? Why?

The objective of TEPOS network has been very stable over time. During the first years (20122015), within the ' $100 \%$-RES Communities' European project, CLER had to conform to the Intelligent Energy Europe vision and interest - but this left room for innovation. Afterwards, national financing took over and CLER could jointly define yearly work programmes with the TEPOS board, which enjoyed practitioners' legitimacy.

\section{Local initiatives in the climate energy domain}

Q. How would you (your network) define a local initiative in the climate energy domain today?

The definition of TEPOS mainly comes from practice and emerged through the exchanges with representatives of founding territories in 2010. CLER was also inspired by the guiding principles for energy autonomy proposed by Hermann Scheer (2007), a German MP. A positive energy territory endorses the "négaWatt" ${ }^{12}$ approach based on the following principles: sufficiency, efficiency, renewables. Later, CLER endorsed a simplified definition shared by the ' $100 \%$-RES communities' EU project. This emphasizes the will and ability to cover the energy demand entirely (and even more) by renewable energy sources for electricity, heating and mobility, and for a political, strategic, systemic and sustainable approach to energy. Regional value creation is also an important dimension.

\footnotetext{
${ }^{11}$ French Law for the 'Energy Transition for the Green Growth (TECV)', dated 17 August 2015.

12 négaWatt is a French NGO that gathers together experts in the energy field, is designing an energy transition scenario for 2050 and advocates its implementation.
} 
We illustrate this with a 'flower' (Figure 1).

[Figure 1 here] Figure 1: Issues and interests that can be included in the 100\%-RES

community vision (source, CLER, 2012).

Q. Is it important to have a 'definition' of what a local initiatives entails? Why?

Within the ' $100 \%$-RES Communities' project, we have developed a common definition and common criteria to be able to display all pioneering regions on a single European map. The labelling, however, has not been much promoted because of translation issues, because of the availability of other visible international frameworks (e.g. international Go $100 \% \mathrm{RE}$ campaign), or because in most countries almost no local authorities have committed themselves to reach $100 \%$ RE.

CLER considers that there is no necessity to define TEPOS more precisely than by its two basic pillars: 1) having the objective and capacity to reach $100 \%$ renewable energy, and 2) promoting an approach in favour of local development.

In France, the fast-evolving interest of institutional partners in the TEPOS concept induced CLER to register itself as a trademark to control its uses. This was important when the Ministry of Environment introduced the concept of 'positive energy territory' in a draft of the future French energy transition Law, and rapidly adjusted the name to 'positive energy territory for the green growth' (TEPCV) accordingly. Still, although the definition has similarities, the two TEPOS pillars are not even listed in the definition of the TEPCV.

Q. Was this definition different in the past? If yes, how did it evolve in the past and why?

From CLER point of view, the general definition of TEPOS has not changed over time. That said, as soon as the French Ministry started to promote the TEPCV variant, it became clear that it significantly modified the way people understood what a 'positive energy territory' is.

Q. Does this definition guide your action as a network? How?

Yes, quite clearly. $100 \%$ REN means that local actions must be ambitious and match or outstrip national and international targets. Local development means that expected socioeconomic benefits of the energy transition should drive the decision process as much as or even more than its environmental benefits (seeing that the energy transition is good for both).

\section{Justice issues}

Q. Are justice issues important in the way you define your network activity or in your practice? In what way and to what extent?

Justice issues have been raised in relation to three issues.

Rural areas witness a deep mutation in the field of energy: from simple consumers, they are becoming energy producers for their own needs and also exporters to neighbourhood (urban) territories. This on-going transformation is essential for a creating new value for rural territories, which would otherwise be further put at risk by their energy bill (transport, housing). Initiating the TEPOS network was not formalised by CLER as a justice issue, yet it clearly falls under this heading. At the end of the 2010s, only large local authorities were 
taken into account by public policies favouring local energy initiatives. Setting up TEPOS provided an arena for the empowerment of mainly small rural local authorities and put this specific target group on the agenda of public institutions. It thus contributed to restoring balance.

For instance, the recent TEPCV national call for projects has evenly supported small rural territories and big cities. CLER defended the idea that we would be better off investing the limited amount of funding allotted to this call in small rural territories as 'seed money' to support capacity building (what we call 'territorial intelligence') in order for them to apply for further funding, develop new projects, generate added local value, local development and political autonomy in the long term.

A second issue relates to the debate about the per-equation of the electricity price meaning that the price of electricity has been historically constructed so as to be equal in any part of the French territory. The per-equation attests to a conception of justice according to which all electricity consumers share equally the burden of unequal proximity to electricity production and distribution. Yet it also constitutes a barrier to the development of local energy transition projects, if only because it provides a convenient justification to maintain the monopoly of the grid distribution operator, who does not actively support the reduction of nuclear energy and the integration of renewable energies. The TEPOS network is calling for a new and more adaptive type of solidarity.

Finally, maintaining that the energy transition is the key to a sustainable and fair future, CLER naturally started a national programme on fuel poverty in 2007 . The TEPOS network is therefore increasingly integrating the issue of fuel poverty in its activities (conferences, webinars, mailing lists, etc).

\section{The mutual relation between your network and public policies}

Q. What does your network seek to achieve or obtain in public policy?

CLER thinks that local and regional action is crucial to tackle climate change, resources and fossil fuel rarefaction, to ensure energy independence and eventually to develop distributed prosperity. In signing the TEPOS charter, network members acknowledge that rural territories can and must play an active role in the re-appropriation of energy issues by all citizens, elected persons and socio-economical actors. They call on central and regional governments to set up favourable conditions for the local energy transition.

Q. What have your actual main achievements been in these respects? Has your network actually influenced public policy in your country? How and to what extent?

CLER has always taken part in the national debates or processes about energy or the environment in France $(2003,2007)$, even before the establishment of the TEPOS network. In 2007, during a major national debate about the environment - the Grenelle de l'Environnement (2007-2009) - CLER published more than 20 years of fieldwork feedback [If referring to fieldwork, then '... 20 years of fieldwork feedback'; if to information in the field of energy, then '... 20 years of feedback in the field ... ']about the development of renewable energies and energy savings ${ }^{13}$. It played an active role in the report of the 'Grenelle' committee about renewable energies.

\footnotetext{
13 A note: 'Subjects or citizens? Elements for a grey book on energy in France', 6 April 2007 ; and a book Change Direction (2007)
} 
More recently, TEPOS flagship territories (e.g. Le Mené, Montdidier) were at the heart of the national debate on the energy transition that preceded the $2014 \mathrm{draft}$ for the energy transition law. This time, exchanges with the cabinet of the Ministry of Environment and participation in preparatory conferences allowed CLER to flag the TEPOS's experience and content publicly and to advocate its vision.

Q. How would you define today your place and role in relation to public policy in your country?

At the early stage of the TEPCV programme, the Ministry of Environment did not take the TEPOS network seriously. CLER, however, benefited indirectly from the ministerial communication on TEPCV, as a significant number of the candidates selected for support 50 between February 2015 and May 2017 - became TEPOS members at the invitation of CLER.

As members of the TEPOS network started to express criticisms of the Ministry services' implementation of the TEPCV programme, we undertook an internal survey ${ }^{14}$, which noted several limits (clarity, transparency, objectives) and made concrete proposals to improve realisation. The survey report got good media coverage and provided CLER with the opportunity to flag its existence as a representative of the historical TEPOS. Since then, the Ministry of Environment has maintained regular contact with CLER to coordinate our actions. Eventually, in 2017, the Ministry financed one fourth (50k€) of TEPOS's annual budget.

Q. Was this different in the past? How did this evolve? Can you distinguish different phases?

The Grenelle Laws ${ }^{15}$ (2009) have brought improvements, but roughly speaking no measures for further decentralisation in the field of energy. Back in 2010, only a few local authorities were members of CLER network. We first had to build our legitimacy in pioneering and activist local authorities. As several of them endorsed the TEPOS concept as a banner, local authorities started to look upon the TEPOS and CLER networks as important players. Through TEPOS and its TEPCV variant, CLER's ideas and proposals on the territorial organisation of energy eventually prevailed in the landscape.

Q. Has public policy been important in supporting your network? If yes, to what extent?

CLER's annual budget equals about 1 million euros, including the TEPOS network subbudget of around 150-200k€. Only 15\% of CLER resources come from membership fees. CLER has always had to look for external financing opportunities. In France, the context for the regional energy transition has been improving only recently, after the Grenelle Laws, and this is why CLER often coordinated or participated in European projects.

In regard to semantics, the fact that CLER adopted in 2010 the specific and not preexisting concept of 'positive energy territory' was absolutely decisive in embedding us in a broad national movement. The Ministry would never have branded ' $100 \%$ renewable energy territory' its TEPCV programme: indeed, this target is politically sensitive and the Minister could not have made her invention using an already familiar and everyday expression.

The financing of CLER activities is a coincidence rather than the fruit of a structured policy or a political will. After all, CLER managed to get financial support from national

\footnotetext{
14 'Report from the TEPOS network on the TEPCV call for projects': http://www.territoires-energiepositive.fr/actualites/rapport-d-enquete-au-sein-du-reseau-tepos-sur-1-appel-a-projets-tepcv

15 The Grenelle Laws (I and II) are two successive French laws adopted ( in 2009 and 2010 respectively) after a national debate about the environment - the Grenelle de l'Environnement - which took place during the summer and autumn of 2007.
} 
institutions only after the Ministry had integrated the 'positive energy territory' concept into the law. Still, it has proved difficult to balance the TEPOS budget. Negotiations must be started again each year and their outcome is sometimes subject to the final discretionary decision of politicians.

\section{Q. How do you perceive changes in the past in this respect?}

Strictly speaking, the TEPOS network is not supported by public policies per se. It is supported by individuals, who within their institution appreciate the added value of our activities and are able to influence the financing decisions.

Our network is rather embedded in a flow of favourable public policies, which were not necessarily initially aimed at supporting its action. No structural changes over the last years could be invoked in order to explain that CLER is better supported now than before.

Q. How do you envision the future in the short term?

The TEPCV programme was directly and strongly attached to the character of the Minister Ségolène Royal, who widely and personally publicised it ${ }^{16}$. After the presidential elections (May 2017), this programme and the financing that made it concrete have vanished entirely. To date, we are not sure what's next.

Nonetheless, the approach to energy in France has changed over the last two to three years, and there is no returning to the previous situation. The energy transition law and the TEPCV programme have together resulted in a 'cultural unlocking' of the crucial role that local energy transition can play in the French national energy transition.

Legal, technical and financial lock-in still persist, such as the legal impossibility to contract with distribution grid operators other than the national monopoly Enedis, or the ongoing change from feed-in tariffs to market instruments for renewable energy that are less accessible to local communities. They hamper effective action by the local authorities.

However, since neither the regional energy transition nor the TEPOS network waited for the TEPCV programme to emerge (it was just a huge catalyser), they should both survive and even grow in a changing context by seizing new financing opportunities, possibly again at European level.

\section{3. deENet and the $100 \%$-RE-Regions network}

\section{The Network}

Q. How would you define your network and its objective today?

deENet was founded in 2003 as a competence network and cluster facilitating the development of decentralised energy technologies. It assembled about 100 companies, service providers, local authorities and research institutes based in the region of Northern Hesse. It covers the entire 'supply chain' of decentralised energy technologies - from R\&D to planning, design, production, operation, education and training. deENet initiated and facilitated the development of 100\%-RE-Regions in Germany by providing regions with a service platform. The implementation of the $100 \%$-RE-target based on decentralized energy production, consumption and a systemic socio-technological

\footnotetext{
${ }^{16}$ The TEPCV programme was financed under a special 'Fund for the Energy Transition' (750 million euros).
} 
approach is the key objective of the network along with achieving energy independence, stabilising energy prices and generating local economic value, to name only a few other goals.

$100 \%$-RE-Regions usually represent municipalities or counties, sometimes large cities (e.g. Rostock, Frankfurt am Main and Osnabrück). They are committed to achieving selfsufficiency based on regionally available RE sources. Today the network is composed of 154 $100 \%$-RE-Regions, representing 24 million inhabitants and $128.000 \mathrm{~km}^{2}$, equalizing more than $30 \%$ of Germany's surface area.

\section{Q. When and how did your network emerge?}

In the 1980s, the first stakeholders - medium-sized companies, the regional development agency and the University of Kassel) all active in the field of decentralised energy production and consumption - collaborated in Northern Hesse. Throughout the 1990s, as the narrative about a regional energy transition provided a breeding ground for pioneering initiatives, ${ }^{17}$ this collaboration matured and the deENet cluster expanded.

From 2003 to 2007, deENet's activity depended on the good will and funding of the Hessian Economics Ministry and local energy enterprises. Some of the first local projects ${ }^{18}$ directed attention to the region and the network. This allowed us to acquire projects that fostered the diffusion and implementation of climate protection action plans at the municipal level.

In 2007, a project ${ }^{19}$ aimed at accompanying the rise of the decentralized energy transition in villages and counties received national funding. As part of this project, deENet worked with local actors in order to generate an overview on the existing $100 \%$-RE initiatives and identify strategic success factors (period: 2007-2010). We then worked on the establishment of a national networking and service platform for 100\%-RE-Regions (period: 2010-2014). A key service represented the organisation of the national 100\%-RE-Regions conference, which has attracted annually about 800 participants since 2009 .

In 2012, the 100\%-RE-Regions network's reputation allowed deENet to join the European '100\%-RES Communities' project, coordinated by CLER.

In 2013, national funding came to a scheduled end and the 100\%-RE-Regions network had to be sustained with limited resources. This difficult situation has been managed via small co-financing solutions from ongoing third-party projects.

Q. What were the main steps and the politics in the network's process of structuration?

The $100 \%$-RE-Regions network is based on a vision of a ' $100 \%$-RE-Region', which bundles together ideas of community spirit, energy security and local value creation. The goals of environmental and climate protection had, however, been spread much earlier by several local pioneers such as Güssing (Austria), Jühnde (Lower Saxony, Germany) and the island of Pellworm (North Frisia, Germany).

In 2007, in the favourable context of the German Renewable Energy Act (REA) and the subsequent 'solar-boom', the funding of the 100\%-RE-Regions project generated a strong dynamic. The 100\%-RE-Regions network gathered together actors and ideas and contributed to the diffusion of innovative practices.

\footnotetext{
${ }^{17}$ Among this group of pioneers were Freiburg (1993), Lübow-Krassow (1997) and Fürstenfeldbruck (2000). See also Tischer, M., Stöhr, M., Lurz, M., and Karg, L. (2006): Auf dem Weg zur 100\% Erneuerbare Energien Region. Handbuch für eine nachhaltige Energieversorgung von Regionen, B.A.U.M. Consult, Munich.

${ }^{18}$ Such as the 'Roadmap 2010 Northern Hesse', which explored the extent to which renewable energy could contribute to job creation and added value in Hesse.

${ }^{19}$ Entitled: 'Development perspectives for sustainable 100\%-Renewable-Energy-Regions in Germany'
} 
The influence of deENet's work on energy policies started by demonstrating that $100 \%$-RE was technically feasible, socio-ecologically desirable and economically viable. To 'prove' these arguments deENet assembled competences and skills, advertised beacon projects and developed monitoring and performance tools. Our objectives then were to: 1 ) identify the key actors in the local projects, 2) comprehend the feasibility of $100 \%$-RE, and 3 ) elaborate on how $100 \%-\mathrm{RE}$ can be achieved concretely and inspire imitators.

In the early network-phase, the message of the $100 \%$-RE-pioneers spilled-over to neighbouring regions. It then reached the country and European level, and later even beyond, via international cooperation (e.g. World Future Council, 100\%-RE campaign, cooperation with Japanese regions, communities and scientists in the post-Fukushima context). Thus the idea of the 100\%-RE-Regions network ended-up shaping a political argument, which even made its way abroad.

Q. Did the objective of your network evolve since its creation? Why?

The development of the 100\%-RE-Regions network was not a typical grassroots movement. Rather, we see it as an innovation process built on and evolving out of scattered existing grassroots initiatives. We laid the foundations for developing a decentralized energy system in the region of Northern Hesse and, as time passed, the targeted audience broadened to include actors outside the region. We emphasised a transdisciplinary approach to develop tools and criteria for assessing the $100 \%$-RE-Regions' performances. While the early period of the $100 \%$-RE-Regions network focused on public engagement, technological feasibilities and business models, to name only a few activities, increasing attention was later directed towards issues of sustainable lifestyles embedded in the infrastructural and institutional setting of 100\%-RE-Regions.

\section{Local initiative in the climate energy domain}

Q. How would you (your network) define today a local initiative in the climate energy domain?

deENet has reflected on the 100\%-RE-Regions experience and published its insights in numerous newspapers and books ${ }^{20}$. This reflective, scientific flanking of the $100 \%$-RERegions project led to elaborate a cross-cutting framework, which distinguishes normative, spatial, thematic and temporal dimensions in the development of a 100\%-RE-Region (deENet, Moser \& Hoppenbrock, 2008) (Figure 2):

[Figure 2 here] An integrated model for achieving a 100\%-RE-Ideal-Region (deENet, Moser

\& Hoppenbrock, 2008)

The normative dimension encompasses values and principles guiding the approach. It frames a mission statement that suggests overwhelmingly covering a region's total final energy consumption - electricity, heating/cooling and mobility -by RE. The ' $100 \%$ ' goal should not be confused with energy autarky; rather it stresses the objective of a 100\%-annual-balancesheet-supply and the necessity of an inter-regional energy trade. As a political vision, it serves

\footnotetext{
${ }^{20}$ A list of the $100 \%$-RE network publications can be found here: $\underline{\text { http://www.100- }}$ ee.de/projekt/inhalte/publikationen/
} 
as a symbol suggesting a strategy based as much on RE as on socio-technical activities contributing to absolute reductions and energy efficiency improvements.

The remaining three dimensions allow us to embrace the manner in which 100\%-RERegions evolve in space and time, covering different topics and policies ranging from smallscale projects to systemic shifts, such as those pertaining to mobility. They encapsulate steps in the socio-political construction of a 100\%-RE-Region, ranging from passing sector-specific resolutions through analysing the broader $100 \%$-potential to adopting a general, legallybinding 100\%-RE-target and generating opportunities for rural-urban or multi-level cooperation. At this mature development stage, the transition process ideally finds increasing resonance in the population and actors and citizens experiment with less resource-intensive lifestyles.

Q. Is it important to have a 'definition' of what a local initiative entails? Why?

For deENet it is important to employ such a definition because it generates a basis for identification, political legitimation and a future-oriented vision. This includes generating constant evidence regarding the technological feasibility, economic viability and sociopolitical desirability of a $100 \%$-RE-transition. Here the reference to and showcase of actually lived and 'working' 100\%-RE-practices in selected places provides a motivational function. Moreover, the $100 \%$-RE-Regions conference served as a stage for these examples, while also providing a 'safe space' for issues and solution to be critically discussed.

Q. Was this definition different in the past? If yes, how did it evolve in the past and why?

The definition of local initiatives has not changed significantly because it was framed from the very beginning as a long-term vision. Importantly, this included the space for individual regions to depart from this vision in a reflective way.

During deENet's early period, its approach to decentralisation was not well-known and it was important to publicise experiences as well as to promote a knowledge-transfer. Later, more national climate initiatives received funds, which multiplied the options for support and helped to diffuse this specific knowledge.

Q. Does this definition guide your action as a network? How?

Based on its experience, deENet has developed an outline of success factors and areas of activity that are relevant when implementing a 100\%-RE-strategy. These are not mandatory but indicative conditions for success (Table 1).

[Table 1, here] Success factors of a 100\%-RE-strategy

On this basis deENet has been targeting two actor-categories: local key actors (e.g. mayors, head of county authorities) responsible for coordinating a regional energy transition, and operating actors such as cooperatives, municipal utilities, planning and consulting offices. Specific tools and monitoring concepts were developed to propel an effective collaboration between them. We experienced that when this collaboration intensifies, which happens progressively, the network platform ideally becomes redundant and the regions run their activities autonomously: they enhance their unique expertise and share it with other network participants. The network platform then operates as a mediator and sustains the relationships between its participants. 
Q. How do you perceive national differences with respect to this definition?

The differences between the French and the German networks chiefly lie in their processes of emergence. In France, due to political and financial reasons, this process was initially more difficult. By contrast, deENet has been supported by national funding relatively early and thus developed dynamically. This was also perceptible in the '100\%-RES Communities' European project.

\section{Justice issues}

Q. Are justice issues important in the way you define your network activity or in your practice? In what way and to what extent?

Although important, justice issues are not central to how we frame our activity and practice, justice as a norm provides a frame for climate protection and the (regional) energy transition, notably in the adoption of national regulations. While some regulations, such as the REA, have been beneficial to $100 \%$-RE-Regions, the regional or decentralized level is more 'impacted by' than 'co-designer of' this frame.

One entry point for us is the extent to which the legal framework behind national support for RE allows for equal access. The recent evolution of the legal conditions behind national support (REA-reforms) have altered and limited this access for small actors. Asymmetries also are important for structural and discursive power in national decisionmaking processes. Big utilities strongly shaped the media debate some years ago about excessively high electricity costs, allegedly caused by the REA.

'Social justice' as a concept did not literally serve as a core frame for the regional energy transition in Germany. Rather, 'citizen energy' and 'community energy', to name two prominent examples, were used to portray the many local and regional energy transition initiatives as a just socio-ecologically counter-draft to the 'central' energy transition. The $100 \%$-RE-Regions future-oriented, ideal-type embraces the ideas of an energy transition engaging the broadest possible coalition of actors and citizens, and distributing as equally as possible its costs and benefits. It also builds on an understanding of a sustainability transition as being normatively founded in inter and intragenerational justice.

\section{The mutual relation between your network and public policies}

Q. What does your network seek to achieve in public policy?

deENet does not represent what we would call a politically-oriented network. It 'pragmatically' addresses local companies, local authorities and communities. Nevertheless, its work has influenced different governance levels, including the Länder (the German federal states) and the national level, especially by mapping and assessing 100\% RE-Regions initiatives and their performance. The resulting 100\%-RE-regions map has been used by various actors to propagate a decentralised energy transition nationally and internationally. Consequently, what did not necessarily start as a political programme has been picked-up widely to push a political issue. 
Q. What have been your main achievements in this respect? Has your network actually influenced public policy in your country? How and to what extent?

Our greatest contribution concerns the transition process at the level of local authorities, communities and regions. As a networking and service platform, deENet helped front-running $100 \%$-RE candidates to reflect on their work, to make these efforts visible and to acquire funding. The network was important in co-constructing a positive narrative on community energy and decentralized approaches, and to propel media representation and knowledge exchange.

Q. How would you define today your place and role in your country's public policy?

While deENet and the 100\%-RE-Regions network do not play a significant role anymore in the political perception - the network's institutional 'left-over' is a small annual conference in Kassel organised by the 'Future Forum Energiewende' - the concept of decentralisation and the $100 \%$-RE idea have penetrated the political and scientific discourse, and are considered realistic options.

deENet's idea to create a network reaching beyond the regional niche has also been embraced by other institutions as part of long-term strategy. The responsibility for the network services and membership base has been informally taken over by the Federal Environment Agency, the Renewable Energies Agency and the Climate Alliance, all three supporters of the former 100\%-RE-Regions conference.

Cooperation between German and European 100\%-RE-networks on the one hand and Japanese and American 100\%-RE networks on the other has intensified progressively. Hence the underlying ideas of the 100\%-RE approach also reach out and have been institutionalised in the international climate regime. The network of ICLEI, for instance, is a central platform and actor in fostering the diffusion of $100 \%-\mathrm{RE}$ at a global scale.

Q. Was this different in the past? How did this evolve? Can you distinguish between phases?

Recently, the overall political context has become more ambivalent. In a nutshell, while the regional 100\%-RE approach is being increasingly criticised and rejected at the national level, there still exists visible support of it by subnational elected politicians.

In 2008, the (oppositional) Green Party postulated a political 100\%-RE-target by 2050. The coalition government, however, increasingly regarded this as unfeasible, economically expensive and socially unfair. It is currently using development corridors for the 'controlled' expansion of RE, enforced by a tendering system that limits the possibility for small actors to invest in local energy projects and to co-shape regional approaches.

By contrast, the German federal states are more supportive of and connected to municipal action. They possess a steering capacity via spatial planning of wind, solar and geothermal energy development. In addition, they are legally responsible for municipal concerns. The Green Party participates in the government of some German federal states, which have endorsed a 100\%-RE-target and declared that it can be achieved only in cooperation with committed municipalities.

Q. Has public policy been important in supporting your network? If yes, to what extent?

deENet would not have been as influential as it has been without the support of public policies. Some people in the national institutions have been crucial in supporting deENet through the $100 \%$-RE-project when it was still a small platform. 
Problematic, however, is that projects can be funded only twice in Germany. Projects need to become self-sustaining soon, which is difficult in the field of climate protection and the energy transition since these are not compulsory tasks for municipalities. For the federal states, these areas are generally not priorities.

\section{Q. How do you perceive changes in the past in this respect?}

Considering the political attitude towards 100\%-RE in retrospect, it seems that until 2009, national policy was neutral towards 100\%-RE-Regions; from 2010 until 2012 it was slightly positive; and since 2013, its attitude has turned increasingly negative. The influence of the $100 \%$-RE-Regions network has become visible at a national policy level and triggered political reactions. By contrast, the German federal states see 100\%-RE-Regions as overwhelmingly positive and the support is somewhat growing.

Q. How do you envision the future in the short-term?

Important changes have recently taken place. In some ways, there seems to be a shift from a decentralised to a centralised energy system design.

Important figures or organisations that were role models and pioneers for the energy transition in Germany have disappeared - through the death of some of the protagonists of the decentralised energy transition (e.g. Hermann Scheer, Günther Cramer/SMA, Jürgen Schmid/IWES), the end of political mandates (e.g. Josef Fell/ Green Party/ MP), company sales (e.g. Juwi), closures or staff turnover. Meanwhile, new actors have appeared - such as the 'Agora for the Energy Turn' (Agora Energiewende) or the 'Alliance of Energy Villages' (BündnisBürgerenergie) - but these actors support the municipal energy transition only to a limited extent because they employ different normative development concepts.

Further, the changes in the institutional context (e.g. the shift of RE away from the responsibility of the Environment Ministry to the Economics Ministry, the recent reforms of the REA) hamper a decentralized energy transition. Self-generated-PV-electricity is now taxed; the value of the feed-in tariff has decreased in view of transitioning towards a tendering model.

Although this context complicates our financing and action, the thematic/conceptual breadth of the energy transition is constantly allowing niches to open-up and for local activities to acquire funding. Yet the different sectors of the energy transition are affected differently. Overall, regions are particularly successful with the expansion of RE, but they have modest results in energy efficiency or sustainable mobility infrastructures.

In future, it seems as if the municipal approach will suffer under the new laws. Emerging markets will arise in the areas of mobility and lifestyles, networking and digitalisation. There will be new steps, laws, alliances or ministries engaged in all the fields working for climate protection. The dilemma that remains, however, is that all countries at the COP 21 decided on limiting the temperature rise to 1.5 degrees while imposing restrictions on the necessary support.

\section{Reflecting on the exchanges, the art of working 'in a flow'}

\section{Two different networks}

In spite of sharing important commonalties and being regarded as homologues by their 
respective representatives, the networks considered in this paper are also quite different. This is summarised in Table 2.

[Table 2 here] Table 2: Comparison of the two networks

Both networks see themselves as national networks; they both work for the development of local/regional actions with a territorial dimension with the aim of addressing climate change; and they both advocate the development of renewable energies (100\%-RE) and the role of local authorities to do so. While they both have clear political goals decentralised energy development (deENet), energy autonomy and local development (TEPOS), expressed in the shared reference to Herman Scheer - they define themselves and see their action in different ways.

deENet defines itself as a technical and competence network supporting the decentralised development of energy technologies. While emphasizing multiple dimensions of local initiatives, its approach to competence provision and development processes borrows from the culture of engineering and economics, through benchmarking, measurement, the stylisation of innovative practices and the circulation of learning. Interestingly, while such a practice seems close to the role of intermediaries depicted by the transition management literature (Hargreaves et al. 2013; Geels and Deuten, 2006), the network borrows this academic strand of niche/regime language. ${ }^{21}$

In contrast, TEPOS defines itself as a grassroots initiative and flags a strongly politicised vision of energy (energy autonomy, social economy, citizen participation), in which the reference to Herman Scheer is central. Local development and a multi-dimensional (flower) vision of sustainable development (actually close to agenda 21) underpin a practice of networking which foregrounds the sharing of returns on experience and a political vision made explicit in the TEPOS charter. Here the sharing of experience is not fostered by prioritising formalised learnings and devising ideal-types, but by fostering direct exchanges, a practice which has been characterised as part of grassroots innovation (Seyfang and Longhurst, 2013).

The origin of the networks somewhat mirrors these differences in practices: deENet traces itself to a regional 'energy cluster' which then grew national; TEPOS stems from an NGOs and territorial (Mené) network which directly established itself as a national grassroots network.

They also had different processes of emergence and growth. The TEPOS network has enjoyed progressive growth, applying for European money and back-staging some priorities of action until a recent change in the French policy context allowed for more tailor-made funding. The 100\%-RE-regions network emerged in the context of already existing pioneering grassroots initiatives and rising energy transition vision in Germany, and soon found federal support. This was significant but remained limited in time, putting the network in a difficult position.

Last but not least, their relation to public policy in their respective countries shares significant commonalties even though they have had contrasting trajectories in the recent past. Both networks advocate the importance of a local / decentralised energy transition; both are critical of public policy in their country while recognising the importance of the support they get from it (when they do). Interestingly, both networks also underline the decisive importance of certain persons/individuals in the national/federal institutions for acquiring funding.

\footnotetext{
${ }^{21}$ Also explicit graphic representations of the path of local initiatives in niche, regime and landscape terms and schematisation.
} 
Both network accounts bear witness to national contexts that have significantly evolved over the recent period. In Germany, in spite of an emphasis on the energy turn, the deENet account points to a turn towards more federal, economic and industrial steering in the energy transition, which makes local initiatives less easy to undertake (revision of the REA favouring larger scale investments and investors) ${ }^{22}$. In France, the TEPOS account observes a recent opening up to local initiatives with the adoption of the energy transition law in $2015 .^{23}$ The 'cultural unlocking' referred to by the TEPOS representative indicates that, for the first time, territories and regions are not only mentioned but also called upon to play their part in the deployment of French energy policy. This means increased recognition and support, even if the overall institutional context remains centralised; for instance, grid concession contracts empower almost exclusively the national distribution grid operator, whereas in Germany the grid can be managed by local companies.

Within these evolving national contexts, the factors that are determining the degree to which networks of local initiatives gain support seem to depend on multiple variables, such as the allocation of issues to the different ministries (Germany), the people working within these institutions and the extent to which they feel concerned with issues of energy transition and local initiatives (in both countries).

\section{'Embedded in a flow'}

Both accounts conclude with visions for the future which foreground dynamics that are larger than the dedicated national policies, whether this consists in being 'embedded in a flow of favourable public policies' (TEPOS) or in the 'thematic breadth of the energy transition [allowing for] small niches to constantly open up' (deENet). Such statements attest to a necessity and an art of playing on multiple levels and scales so as to cut a path for the network through the midst of changing and not always supportive institutions.

National institutions are endowed with a central status and importance in both accounts: they are indeed a source of support and regulations that are decisive for the capacity of local initiatives to develop. Both networks, however, are very aware of the necessity to play on and with multiple scales of actions in order to gain a margin for manoeuvre in changing national contexts. As the TEPOS account states, the network capacity for action is embedded 'in a flow' (of favourable public policies) and does not depend on one single policy or political decision. All the same, the 100\%-RE network emphasizes the differences in support between the national level and the Länder level, or the relay taken by national institutions and NGOs on the management of the network in the current downturn period. This art of working in the flow allows for continuity in identity and action through constant boundary making, encompassing various dimensions.

One important dimension is self-definition and the way in which networks attempt to identify/flag members. Both accounts evince a set of values and objectives held to be selfdefining and stable in time. Politicisation, however, is expressed neither to the same extent nor in the same way. Whereas TEPOS flags a grassroots dimension, a political momentum and a political engagement towards local sustainable development (autonomy, social economy), deENet claims efficiency, competence and steered process in energy technology decentralisation.

\footnotetext{
${ }^{22}$ This turn in German energy policy has been pointed out in the literature (Fuchs, 2013).

${ }^{23}$ The evolution of French energy policy, which has historically been very centralised, has also been analysed (Andriosopoulos and Silvestre, 2017; Nadaï et al., 2014; Szarka, 2006).
} 
Flagging members, demonstrating broad presence (quantification, mapping, labelling) is also part of and boundary-making by scaling objects and developing a new scale of governance (Bulkeley, 2005). Interestingly, the eventual failure of the attempt to harmonise a definition of ' $100 \%$-RES communities' and develop a European-wide label testifies to tensions between the interest in pooling in order to lean on new scales of action and the divergent (if not competing) transnational agendas and strategies of the different networks.

Demonstrating the feasibility of objectives is also essential in scaling up action. Beacon projects are like a proof; they prove that these objectives are possible and real, and this gives the network legitimacy. Yet scaling up should not be looked upon solely as gaining recognition in and from higher institutional levels. The approach to public policy also is one of evolving the way in which public policy approaches energy transition to reshape scales and hierarchies. The TEPOS account bears witness to a progressive recognition by policy-makers, access to and influence on policy making (ranging from 'societal' actor to 'expert' in a national committees). The deENet account emphasises more the indirect influence of beacon projects inspiring public policy or serving as incubators or test-beds for new policy instruments.

Each in its way, these accounts attest to the necessity of playing on multiple resources - members' contribution, EU funding, regional/local state or national/federal support - in order to secure progressive development. The current fate of deENet, with its fast growth and ensuing crisis, indicates the risk incurred in failing to prevent dependence on a single source of financing.

\section{Justice issues and the politics of assembling}

Justice issues have been introduced during the development of this paper because they were not thematised as such in the initial accounts of the networks. Probing the theme of justice allowed us to point out some issues of distribution and recognition ${ }^{24}$. Distribution mainly indicates unfair repartition of state support to small actors, small territories or small local authorities, because access to this funding is more difficult for small players or because the specificities of these small players are not recognised by existing institutions. This relation between distribution and recognition has been observed in recent UK energy policy. The main point of this focus, however, is to emphasize the need for capability-building for small players (Park, 2012). The imbalance in public policies target publics (big rather than small territories) or the differences in return per euro between small and big players (TEPOS's argument) has not been underlined.

Beyond types of justice, the way in which justice is (or is not) mobilised is related to some degree with the politics of assembling the networks. TEPOS insists upon the necessity of recognising differences between territories, for acknowledging energy poverty, and for reconsidering forms of solidarities around electricity production and pricing as key elements in constructing energy autonomy and a sustainable energy transition. In so doing, it flags justice issues as more political and inherent in its approach than does deEnet, which posits ideas of justice in the (distant) realm of 'norms' and has recourse to more inclusive ideas ('broadest possible coalition of actors and citizens').

As has been explored in different cases (Jonet and Servigné, 2013, Fernandes-Jesus et al 2017 for the transition network; Bailey et al. 2018 for community renewables), justice issues, even when the network discourse marks them, are not always made explicit on the ground. The reasons for this have often to do with a perceived need to remain positive and inclusive in order to recruit (e.g. avoiding negative narrative, avoiding confrontation with existing political and economic powers, not actively considering diversity and power issues

\footnotetext{
24 'Recognition justice' has been defined by Bickerstaff et al. (2013) in the context of climate change as dimension of justice that recognizes and accounts for differences between the concerned parties.
} 
within communities). There is thus a tension between the invocation of justice issues and the politics of assembling a network.

\section{Conclusion}

The close-up of these two networks supports, if only to a limited extent, the view that local initiatives are entering a new period. It definitely points out a remaining unevenness, stopand-go in public policy support to local initiatives in spite of sometimes growing localism in policy discourses.

It also brings with it four conclusions and considerations for research.

The first conclusion concerns the type of niches - i.e. grassroots vs market niches and the work of intermediaries; this has been described in the literature and suggests paying more attention to hybrids ${ }^{25}$. We chose the two networks considered in this paper because they thought they had much in common. They do share a great deal, including their political ends (localisation of energy production and empowerment of rural territories in the energy transition). But while such an objective brings them closer to the politics of the grassroots, the ways in which they play their role as intermediaries are different. In several respects, deEnet is closer to the practice of intermediaries as described by the transition management strand, whereas TEPOS practice is better captured by the description of intermediaries' work in grassroots initiatives.

The second conclusion concerns the work of these intermediaries. Much of the analytical effort has been focused on describing their role for innovation niches or grassroots initiatives (e.g. aggregation of knowledge, creation of an institutional infrastructure, framing and coordinating local-level activities, brokering). The accounts elaborated in this paper place the accent on an additional type of work, namely that of tinkering with multiple supports and embedding action in local-national-supranational networking in order to maintain continuity beyond (stop-and-go) and in the midst of (often centralised) national state action. As a window on two network practices, our paper militates for also devoting attention to how these intermediaries maintain themselves. It also militates for a view that distances itself from 'decentralisation' - even if the term is used by both these practitioners - as a framework opposing the national (the centre) to the local (the de-centred). The foregoing accounts flesh out practices that reflect on both the role and the importance of national policies and politics, partake in multiple scales, and lean on multiple resources in order to construct continuities in action.

The third conclusion is that the two networks of local initiatives under consideration have inspired or are inspiring national policies in multiple ways: directly, by accessing policy arenas and contributing to policy making; indirectly, by publicising beacon experiences that stretch boundaries in how far territories can go in taking charge of climate-energy issues.

Finally, the fourth conclusion concerns justice issues. It is consistent with analyses of other networks (community energy projects, transition network initiatives) which underline that these issues appear to be seldom explicitly discussed or flagged. While these analyses indicate reasons having to do with fear of division or confrontation, our accounts also seem to emphasize a sort of distance from the language of justice. Ideas of justice, except for distributive justice, do not consort easily with the level of practice. Motives or ends of action are only reflectively related to ideas of justice, after probing, and only then can they be identified as markers. Justice issues thus seem bound up with a politics of assembling, either as a marker of federative of action (all fighting for justice) or as a potentially divisive issue.

\footnotetext{
${ }^{25}$ Current research on social innovation might offer constructive ways to pursue ahead in this direction : http://www.transitsocialinnovation.eu,
} 


\section{References}

Andriosopoulos Kostas, and Stephan Silvestre. 2017. French energy policy: A gradual transition, Energy Policy, 106: 376-381

Bailey Ian, and Hoayda Darkal (2018) (Not) talking about justice: justice self- recognition and the integration of energy and environmental-social justice into renewable energy siting. Local Environment, 23(3): 335-351.

Bickerstaff, Karen, Gordon Walker, et Harriet Bulkeley, édeds. 2013. Energy Justice in a Changing Climate: Social Equity and Low-Carbon Energy. 224pp, Zed Books, London.

Bukeley Harriet, 2005, Reconfiguring environmental governance: Towards a politics of scales and networks, Political Geography, 24, 875-902.

CLER-RTE, 2013, 'Go 100\%-RES Communites', https://ec.europa.eu/energy/intelligent/projects/sites/ieeprojects/files/projects/documents/100-res-communities project slides.pdf

Felicetti Andrea. 2013. Localism and the Transition movement, Policy Studies, 34:5-6, 559574.

Fernandes-Jesus Maria, Anabela Carvalho, Lúcia Fernandes \& Sofia Bento. 2017. Community engagement in the Transition movement: views and practices in Portuguese initiatives. Local Environment, 22:12, 1546-1562.

Fuchs Gerhard, and Nele Hinderer. 2016. Towards a low carbon future: a phenomenology of local electricity experiments in Germany, Journal of Cleaner Production, 128: 97-104.

Geels Franck, and J.J., Deuten. 2006. Local and global dynamics in technological development: a socio-cognitive perspective on knowledge flows and lessons from reinforced concrete. Science and Public Policy, 33 (4): 265-275.

Hargreaves, Tom, Sabine Hielscher, Gill Seyfang, and Adrian Smith. 2013. Grassroots innovations in community energy: The role of intermediaries in niche development. Global Environmental Change, 23 (5). pp. 868-880.

Jonet C., and P. Servigne. 2013. Initiatives de transition: la question politique. Mouvements, 75(3), 70-76.

Middlemis, L., Parrish, Bradley D., 2010. Building capacity for low-carbon communities: The role of grass roots initiatives. Energy Policy, 38, 7559-7566.

Moser, P. \& Hoppenbrock, C., 2008, Modelle und gesellschaftliche Prozesse für ein regionales Energiesystem, in George, Wolfgang u. Bonow, Martin (Hrsg.) (2008): Regionales Zukunftsmanagement - Band 2: Energieversorgung, Saarbrücken. S. 72-85.

Nadaï Alain, Olivier Labussière, Ariane Debourdeau, Yannick Régnier, Béatrice Cointe, and Laure Dobigny, (2015) "French Policy Localism: Surfing on 'Positive Energie Territories' (Tepos)”, Energy Policy, 78 (March): 281-29.

Park Jung Jin (2012) Fostering community energy and equal opportunities between communities, Local Environment: The International Journal of Justice and Sustainability, 17:4, 387-408.

Scheer Hermann, 2007, Energy autonomy: the economic, social and technological case for renewable energy, 320pp, Earthscan, London. 
Schot Johan and Frank W. Geels. 2008. Strategic niche management and sustainable innovation journeys: theory, findings, research agenda, and policy, Technology Analysis \& Strategic Management, Vol. 20 (5): September, 537-554

Seyfang, G., 2010. Community action for sustainable housing: Building a low-carbon future. Energy Policy 38(12), 7624-7633.

Seyfang, G., Park, J. J., Smith, A., 2013. A thousand flowers blooming? An examination of community energy in the UK. Energy Policy 61(13), 977-989.

Seyfang, Gill, and N. Longhurst. 2013. Desperately seeking niches: Grassroots innovations and niche development in the community currency field. Global Environmental Change, 23: 881-891.

Seyfang, Gill, Sabine Hielscher, Tom Hargreaves, Tom Martiskainen, and Adrian Smith. 2014. A grassroots sustainable energy niche? Reflections on community energy in the UK. In: Environmental Innovation and Societal Transitions, 13: 21- 44.

Szarka, J., 2006. From inadvertent to reluctant pioneer? Climate strategies and policy style in France. Climate Policy, 5 (6), pp. 627-638

Taylor Aiken Gerald. 2015. (Local-) community for global challenges: carbon conversations, transition towns and governmental elisions. Local Environment, Vol. 20 (7): 764-781.

Taylor Peter J. 2012. Transition towns and world cities: towards green networks of cities. Local Environment, 17:4, 495-508.

Van de Grift Elisabeth, Joost Vervoort and Eefje Cuppe. 2017. Transition Initiatives as Light Intentional Communities: Uncovering Liminality and Friction, Sustainability, 9, 448.

Van der Schoor Tineke, Harro van Lenteb, Bert Scholtensc, and Alexander Peined. 2016. Challenging obduracy: How local communities transform the energy system. Energy Research \& Social Science, (13) 94-105

Walker, G., Devine-Wright, P., 2008. Community renewable energy: What should it mean?, Energy Policy, 36(2), 497-500.

Yalçın-Riollet M., Garabuau-Moussaoui I., Szuba M., 2014. Energy autonomy in Le Mené: A French case of grassroots innovation, Energy Policy, In Press, 
Figure 1: Issues and interests that can be included into the $100 \%$ RES community vision (source, CLER-RTE, 2013).

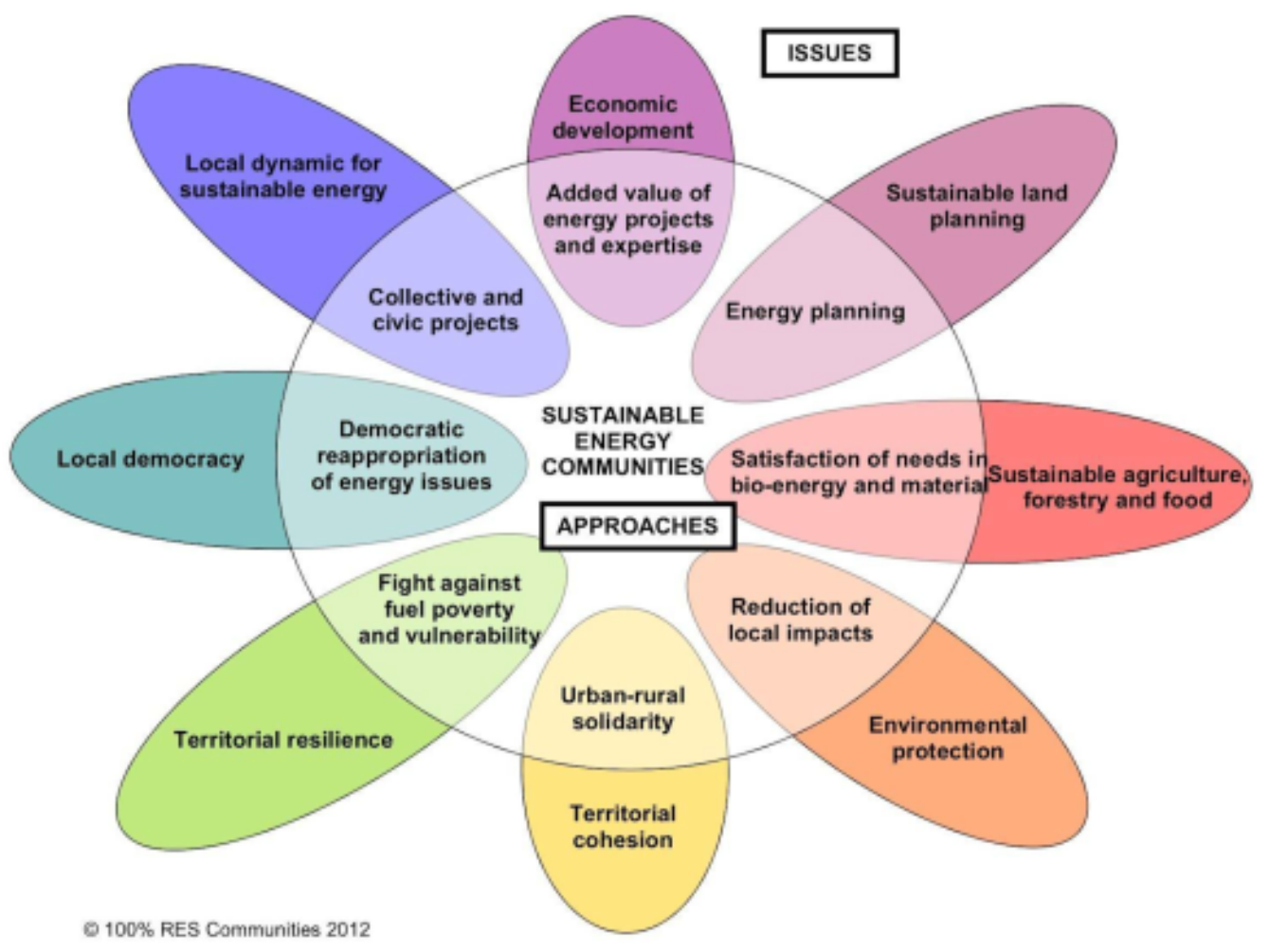


Fig 2

Integrated model for achieving a 100\% RE ideal region (Source: deENet, Moser \&

Hoppenbrock, 2008)

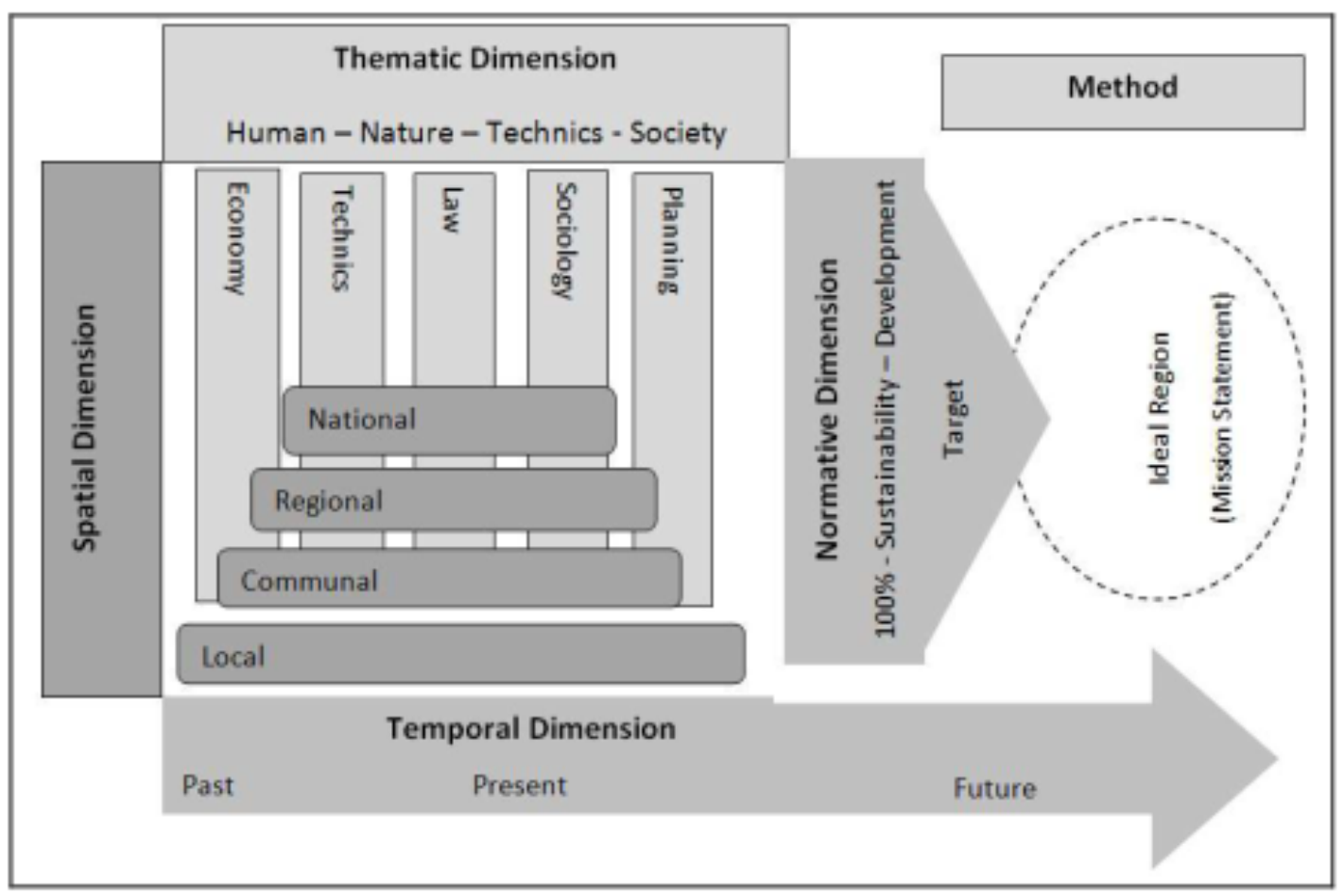

Table 1: Critical factors behind a successful 100\% RE strategy (Source: deENet)

- Board decisions aiming at 100 per cent - resolution at municipal and/or higher administrative level (based on measurable objectives, timelines and financial resources).

- Potential of renewable energy sources - assessment of sustainably exploitable renewable energy potential, efficiency potentials, potentials for energy saving, past and future demand scenarios. Assessment of technologies and their interplay to achieve the target.

- $\quad$ Spatial planning - integrating the energy plan into special plans.

- $\quad$ Pioneers and personalities - responsible and competent persons that push the process forward.

- $\quad$ Added value - renewable energy developed by financial resources and regional actors coming from the region help accumulating added value that stays in the region.

- Participation - regional inhabitants should be integrated into a transparent development process to achieve a high level of acceptance, feeling of team spirit and ownership. Good public engagement and financial participation should also be considered.

- Entrepreneurship - it is important to promote start-ups in the energy sector and related sectors to drive innovations and market development.

- Beacon projects - the realization of single, sometimes small-scale projects makes renewable energies more tangible, deconstruct prejudices, and lowers the threshold for imitation in other places.

- Masterplan - Strategic mid-, short-, and long term planning helps to coordinate steps and paths taken towards 100 per cent renewable energies. 
Table 2: Comparison of the two networks

\begin{tabular}{|c|c|c|}
\hline & CLER TEPOS & DeNet $\mathbf{1 0 0} \%$ RE Regions \\
\hline Objective & \multicolumn{2}{|c|}{$\begin{array}{l}100 \% \text { ReN. } \\
\text { Local/regional action is crucial to address climate change. }\end{array}$} \\
\hline \multirow[t]{2}{*}{ Identity } & \multicolumn{2}{|c|}{ National network of local (territorial/regional) initiatives } \\
\hline & $\begin{array}{l}\text { Grassroots network. } \\
\text { Politicised perspective on energy } \\
\text { (energy autonomy, social } \\
\text { economy, citizen participation) } \\
\text { Reference to Herman Scheer. }\end{array}$ & $\begin{array}{l}\text { Competence network. } \\
\text { Support for the development decentralised } \\
\text { energy technologies. } \\
\text { Reference to Herman Scheer. } \\
\text { Shares conceptual similarities with the } \\
\text { multi-level perspective (MLP). }\end{array}$ \\
\hline Origin & $\begin{array}{l}\text { Emanation from a network of } \\
\text { non-profit organisations and } \\
\text { territorial initiatives (local } \\
\text { development). }\end{array}$ & $\begin{array}{l}\text { Emanation from a network of technical/ } \\
\text { business/ academic actors/local authorities } \\
\text { in Northern Hesse [an 'energy cluster']. }\end{array}$ \\
\hline Development & $\begin{array}{l}\text { 1. Setting up as a national } \\
\text { network } \\
\text { 2. European networking, EU } \\
\text { funding (coord. '100\%-RES } \\
\text { Communities' project) } \\
\text { 3. more recently, national } \\
\text { funding. }\end{array}$ & $\begin{array}{l}\text { 1. Regional network, support from the land } \\
\text { of Northern Hesse } \\
\text { 2. Role/success of pioneering experiences, } \\
\text { access to federal funding (limited in time } \\
2007-2013 \text { ) } \\
\text { 3. EU funding (member of ' } 100 \% \text {-RES } \\
\text { Communities' project) } \\
\text { 4. Shortening of funding. }\end{array}$ \\
\hline $\begin{array}{l}\text { Definition of 'local } \\
\text { initiative' }\end{array}$ & \multicolumn{2}{|c|}{$\begin{array}{l}\text { Key role of local authorities } \\
\text { Territorial dimension of the energy transition }\end{array}$} \\
\hline & $\begin{array}{l}\text { Rural territories. } \\
\text { Local development. } \\
\text { Political approach to energy } \\
\text { (energy autonomy, social } \\
\text { economy, citizen participation). } \\
\text { Sustainable development, multi- } \\
\text { dimensional (flower). }\end{array}$ & $\begin{array}{l}\text { Counties to small cities. } \\
\text { Local (added) value. } \\
\text { Decentralised energy technologies, from } \\
\text { niche to regime (shares conceptual } \\
\text { similarities with the multi-level perspective } \\
\text { (MLP).and transition management). } \\
\text { Process of development, phases and } \\
\text { dimensions (normative, spatial, thematic } \\
\text { and temporal). }\end{array}$ \\
\hline
\end{tabular}




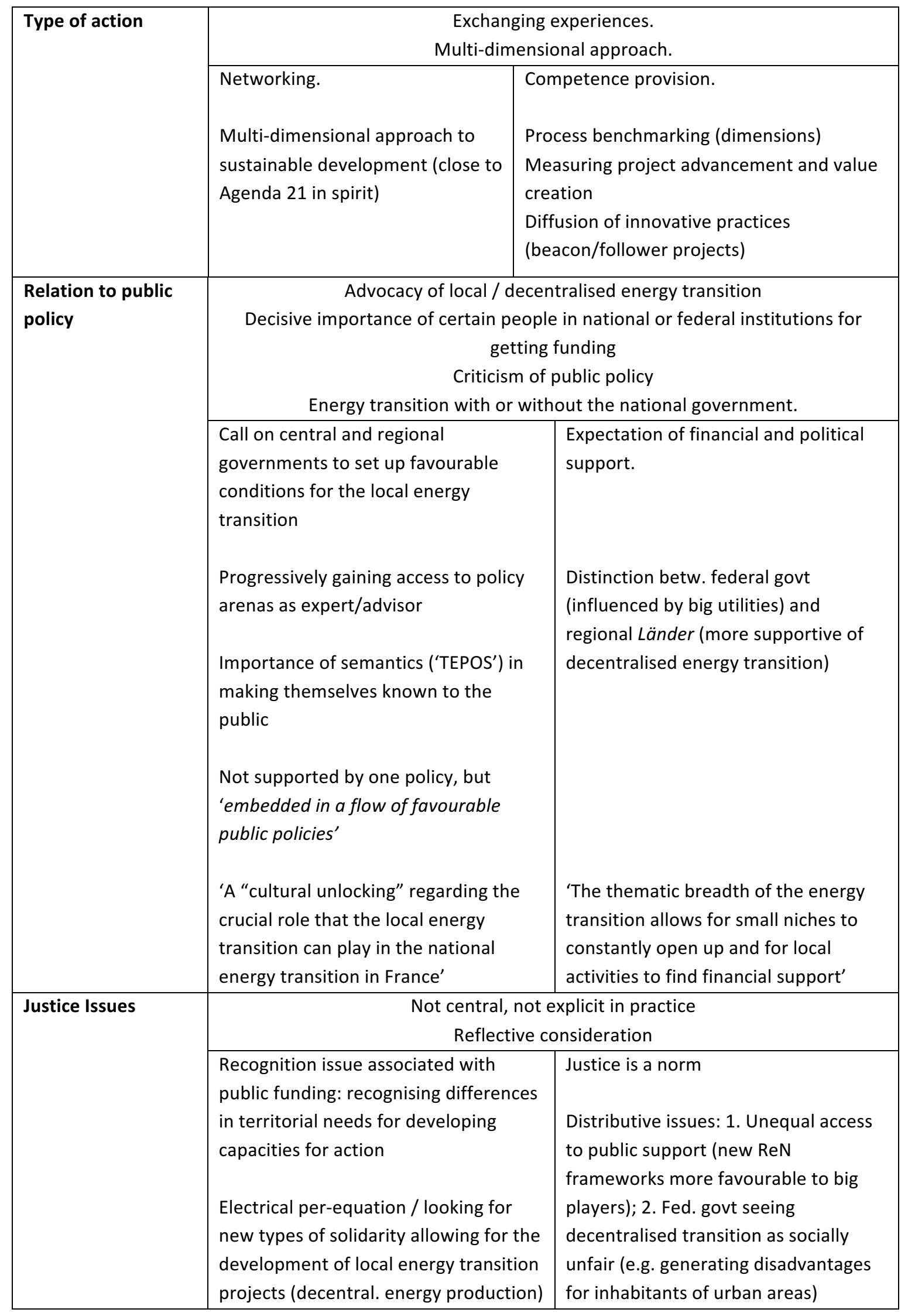

